\title{
Accentuation: A Key Factor of Native Languages in African Philosophy
}

\author{
John Justice Nwankwo \\ Department of Philosophy, Faculty of Humanities, Rivers State University, Port Harcourt, Nigeria
}

Email address:

johnjusticenwankwo@yahoo.com

\section{To cite this article:}

John Justice Nwankwo. Accentuation: A Key Factor of Native Languages in African Philosophy. International Journal of Philosophy. Vol. 9, No. 3, 2021, pp. 178-181. doi: 10.11648/j.ijp.20210903.19

Received: August 12, 2021; Accepted: August 30, 2021; Published: September 13, 2021

\begin{abstract}
The pattern of the pronunciation of words in any part of the world depends on the people's accent. In native languages, what gives a word its meaning is largely dependent on how the word is pronounced. For instance, 'akwha' could mean up to three different things in Etche language and the only way to identify the particular meaning of the use of the word at any point is the accentuation. Thus, accentuation plays a very vital role in the meaning of words in native languages. The absence of accents in words most times leaves such words ambiguous, and sometimes they are used out of context. Accentuation therefore, is very important in the language game of words and their meanings in native Africa. Words are accentuated with marks called diacritical marks. These marks are fixed based on the tone of the word and the tone in turn determine the pronunciation and meaning of the word. Using Etche as a place of reference, this research work therefore seeks to unravel the role of accents in native languages in philosophy. It will use the analytical method of inquiry as it intends to analyze the effects of accentuation in the meaning of words in African languages. This is a fresh area in the field of African philosophy and therefore, the most common challenge encountered as it is also the case with many other researches in African philosophy, is lack of sufficient materials on the topic under research. It also does not in any way pretend to be a close investigation, rather it is open to criticisms, reviews and additions, especially in the context other languages or dialects.
\end{abstract}

Keywords: Accentuation, Factor, Native, Language, Africa, Philosophy

\section{Introduction}

In March 2019, I was to attend a conference in a place called Gbangan. All that was issued to guide me in my journey was the letter of invitation. Unfortunately, my letter only identified Gbangan as the venue for the conference and did not specify where Gbangan is located. On putting my heads together with my outgoing predecessor, we could factor out that it should be located in the Western part of Nigeria, either Ogun or Osun. The rest of the way to decipher the actual location of Gbangan was left for me. I took a flight to Lagos and at the Airport, I asked people how to locate Gbangan, pronouncing ' $a$ ' as ' $\alpha$ ', but nobody seemed to have a clue. It took an intervention of a young man to take a look at what I was trying to pronounce, following the accent of my own local environment. Then he gave the correct pronunciation in the Yoruba accent, there ' $a$ ' was pronounced as 'ó'. That is how powerful accentuation can be; it makes and changes the pronunciation and meaning of the word being pronounced. Ndimele noted that "In Èchiè, a variation in the pitch of the voice can trigger a meaning difference between expressions which are identical in all respects." [1]. The pitch of expression is determined by the accentuation of the word, either as high, medium, low or flat.

This is very emphatic then of the belief of Ludwig Wittgenstein, who "argued that a word or even a sentence has meaning only as a result of the 'rule' of the 'game' being played" [2]. Punctuation marks especially diacritical marks are very important in the language game of giving meaning, since the language game affirms that the meaning of a word or sentence depends on the circumstance surrounding the word or sentence. Meaning depends on those rules guiding the use of the specific words in the circumstance that they are used. This research work therefore falls under the area of philosophy called analytic philosophy and builds upon the provisions of the language game philosophy. It shall be divided into the following topics: abstract, introduction which is ongoing, the concept of accent, relationship between 
accentuation and verbalization, understanding the principle of language game, relationship between language game and accentuation, and conclusion.

\section{The Concept of Accentuation}

Most times, words are ambiguously used without precise elucidation of the actual meaning of the word as at the time of its usage. Sometimes a word could have more than one meaning just like the native words of 'akwha' as seen above. It is therefore necessary to define concepts used for academic purposes especially when need be. It is more significant in an endeavour which involves language game. Hence, it is proper to elucidate the word 'accentuation' which forms the heart of this research study. Accentuation is "the action or fact of accentuating or of being accentuated." [3] BBC English Dictionary defines “"accent' as a mark written above or below certain letters in some languages to show how they are pronounced" [4]. The essence of accents is emphasis. To emphasize certain aspects of some words is not only important, but could completely give new meanings to the words especially in languages with heavy accents. Most of our native languages are embedded with such heavy accents and it is such accents that give the words both their pronunciations and their meanings. The Online Cambridge Dictionary defines accentuation as "... the act of emphasizing a particular feature of something or making something more noticeable ..." [5]. This definition adds the fact that the emphasis is not on the entire word or sentence, but on certain aspect of it. There are certain important aspects, targeted to give both meaning and tone to the words or statement. If is also worthy of note that accentuation can also refer to the way a people speak. It could be that the accents in their native languages influence their accents even for other languages. For instance, in Nigeria, an Akwa Ibom accent may not be the same with Benin accent, even when people influenced by both accents are speaking in English language. However, the context of accentuation in this research work deals with the first meaning of emphasis to convey meanings.

\section{Relationship Between Accentuation and Verbalization}

In Africa, words are accentuated with marks called diacritical marks. These marks are fixed based on the tone of the word and the tone in turn determine the pronunciation and meaning of the word. The word 'akwha' could have three different expressions in Etche: akwhá means 'a cry', 'akwhà' means to 'fall' and 'akwhā means 'egg'. These are three different words but with the same spelling. Another example that can be seen in the word; 'ikhé' means 'strength', ikhē means 'to tie' and ikhè means 'bunch'. In both cases, the only difference is been based on the diacritical marks and its position for each word. If the diacritical marks are taking away, it will become difficult to understand the difference or rather, the three words will adopt the same pronunciation and the same meaning. If not the other possible way of identifying the exact meaning is when the word in question is interpreted within the context of its located. This second option has the challenge of misinterpretation, especially if the word can fit into the sentence with two possible meanings. For instance; akwhá di nma and akwhā di nma. Whereas the first means "it is good to cry", the second means "egg is good". So, the affixture of the punctuation marks which gives meaning to the word is very important in African native languages. For instance, in Etche, Southern part of Nigeria, tone performs both lexical and grammatical functions. While saying this in the sense of general punctuation marks, Sarwan Singh says "Marks of punctuation play very important role in giving intended meaning to the language." [6]. It therefore means that punctuation marks are generally important in conveying meanings, but diacritical marks are much more sensitive in the area of translations. On these marks, language connection says "while these variances in punctuation may not be something that everyday readers of content think about, they are certainly important for professional translation services providers" [7]. Language connection continues thus: "In order to accurately convey the meaning and tone of a translated text, a translator must be aware of how punctuation plays into that." [7]. It is a known reality that words gradually lose their ideal meaning in the process of translations. As true as it is that sometimes it is difficult, the perfect exact meaning of one word in another language may not fit into another meaning. It is also true that improper punctuations or lack of punctuations can also cause a loss of the ideal interpretation of words.

\section{Understanding the Principle of Language Game}

Every use of accents occurs within the context of a language. Therefore, the rules binding languages also binds the principle of accentuation. This is still relatively a new area in philosophy. It is only recently that linguistics occupied with the analysis of sentences and their various internal structures. Writing in 1983, Kerstin Severinson Eklundh wrote; "Only ten years ago, linguists were mostly occupied with the analysis of sentences and their internal structure on various levels". [11]. Between 1983 and 2021 is about 38 years; which shows that discussing the analysis and internal structure of sentences within the context of African Philosophy shows that African Philosophy has reached its global limit. Discussing the inner structure of sentences shows that philosophy as a discipline is interested in the role of languages in human societies.

Philosophy and philosophers shifted attention to language in their philosophical speculations in the mid-nineteenth century. As Wolf citing Wilfred Salars puts it, "Language came to be seen as the "medium of conceptualization,'..." [8]. Gottlob Frege, Bertrand Russell, John Stuart Mill, Ludwig Wittgenstein, members of the Vienna circle (Carl 
Hempel, Rudolf Carnap, and Hans Reichenbach among others), Alfred Tarski, W. V. O. Quine and so on, all contributed towards the analytic movement of language. However, we are more interested in the later work of Ludwig Wittgenstein called Philosophical Investigations (1953). There, Wittgenstein says that language is a diverse, mercurial collection of "language games". For him, languages are goaldirected social activities for which words are just so many tools to get things done, rather than fixed and eternal components in a logical structure. According to Wolf, "Representations, donations and picturing were some of the goals that we might have in playing the language game, but they were hardly the only ones." [8]. These confer some meaning through the establishment of rules since language is not private. According to Wittgenstein, "meaning is use" [9]. But language cannot be reduced to static, simple units rather "Each language is like a game, with its own rules governing its use" [9]. Omoregbe explained the uniqueness of each language as seen in the philosophy of Wittgenstein. It is worth mentioning here that Wittgenstein in his Tractatus Logico-philosophicus held an opposite opinion when he stated that "The world is the totality of fats, not of things" [10]. In this work, Wittgenstein gave an impression of language as static and facts as determinants of language. However, Wittgenstein has realized that language is dynamic and each language is governed by rules and its rules are peculiar to it as it stipulates how to play the language game. Omorgebe, while explaining Wittgenstein further says, "There is no absolute, objective structure for all games because all games are not the same, each is different and has to be played in its own way" [10]. However, Wittgenstein acknowledges similarities and relationships among languages but never the same and their uniqueness must be appreciated and respected.

\section{Relationship Between Language Game and Accentuation}

From the ongoing discussion, it is very clear that there is a close relationship between the accents of words and their meanings in most native languages. If a word could have different meanings as shown above with 'akwha' and 'ikhe', just by a change of the position of the diacritical mark, it shows that accent conveys meanings in African languages and many other native languages. Wittgenstein acknowledges this by saying:

We can think of the whole process of using words... as one of those games by means of which children learn their native language. I will call these games 'language-games' and will sometimes speak of primitive language as a language game. And the process of naming the stones and repeating words after someone might also be called language-games. Think of much of the use of words in games likes a-ring-a-rose. I shall also call the whole, consisting of language and actions into which it is woven, the language game. [9].

Thus, Wittgenstein agrees with rules of accentuation as a language possibility in the process of using words. He notes it as one of the games by means of which children learn their native language. This simply means that without the necessary placements of accents, that conveys meaning, we could not have been able to learn our native languages. Another metaphor that Wittgenstein used to describe languages is that of a tools box. "A language, he says, is like a box of tools" [9]. Then Omoregbe Quotes Wittgenstein:

Think of tools in a toolbox: there is a hammer, plier, a saw, a screw-driver, a rule, a glue-pot, glue, nails, and screws - The functions of words are as diverse as the function of these objects .... It is interesting to compare the multiplicity of the tools in language and of the ways they are used, the multiplicity of kinds of word and sentence, with what logicians have said about the structure of language (including the author of the Tractatus LogicoPhilsophicus) [10].

This explain with greater clarity the fact that every language is made of sentences and every sentence is constituted by words and every word has different components, of which accents play significant roles in native languages. The functions of words, he said, are diverse including giving of meanings. Thus, it is interesting to bring out how accents can give meanings to sentences, words and how tones of expression give meanings to words. This shows that within the boundaries of language game, accents form a very vital part of its content. Accents are part of the tools in the figurative toolbox of the language game.

\section{Conclusion}

The research work being concluded is one of those areas that a non-critical mind would see no need to endeavour to speculate. Yet, attempting to philosophize on it has shown that this is an important area of African philosophy that has not been harnessed. In his work titled "Philosophy: History and problems", Samuel Enoch Stumpf asks "How, more specially, does one who doesn't know his way about find it, or how does the fly escape from the fly bottle?" [12]. This question is reminding us that the only way to solve a problem is by proffering the solution. At a point I time, Wittgenstein agreed that "There is not a philosophical method, though there are indeed methods, like different therapies." [12]. Therefore, we are encouraged to attempt proffering solutions to different philosophical issues through different methods. Just like a person who lost his way needs a map, so the philosophers need language to philosophize. The clarity of such instrument of philosophy like language is therefore not debatable. It is such clarity that this research work was embarked upon as it is the case in our native languages. Since the foundation of African philosophy is based on native principles, first spoken in native languages, the clear assessment of the components of such languages becomes important. Accentuation has shown itself to be one of those components in the language game of native languages. Thus, it must be considered with some level of seriousness as it deserves. 


\section{References}

[1] Ndimele, O. (2005). A Concise Grammer \& Lexicon of Echie. Aba. National Institute for Nigerian Languages, p. 26.

[2] Wikipedia (Retrieved $9^{\text {th }}$ July, 2021). Language Game Philosophy. https://en.m.wikipedia.org, p. 1.

[3] Oxford Language Dictionary (Retrieved) July, 2021). Accentuation. https://www.google.com, p. 1.

[4] BBC English Dictionary (1992). Accentuation. London: Harpercollins Publishers Ltd, p. 6.

[5] Cambridge Dictionary (Retrieved $9^{\text {th }}$ July, 2021). "Accentuation". dictionary.cambridge.org, p. 1.

[6] Singh, S. (March 25, 2015 retrieved $9^{\text {th }}$ July, 2021). Importance of Punctuation Marks. https://www.linkedin.com, p. 1.

[7] Authors LC. (2001. Retrieved $9^{\text {th }}$ July, 2021). Punctuation Marks. In Language Connection. Punctuations, Compete Now Edition. https://www.languageconnection.com, p. 2, 3.

[8] Wolf, M. P. (2006. Retrieved $13^{\text {th }}$ July, 2021). "Philosophy of Language" in Internet Encyclopedia of Philosophy. ISSN 2161002. https://iep.utm.edu, p. 3, 14.

[9] Wittgenstein, L. (1977). Philosophical Investigations. Oxford: Blackwell, p. 43, 123, 161.

[10] Omoregbe, J. (1999). A Simplified History of Western Philosophy, Vol. 3: Comptemporary Philosophy. Lagos: Joja Educational Research and Publishers Ltd, p. 121, 122.

[11] Eklundh, K. S. (1983). The Nation of Language Game - A Natural Unit of Dialogue and Discourse. Sweden: University of Linkoping Studies in Communication, p. 3.

[12] Stumpf, E. S. (1994). Philosophy: History and Problems, $5^{\text {th }}$ edition. U.S.A: MacGraw Hill, Inc, p. 404. 